ISSN: 0213-2079 - ISSN electrónico: 2386-3889

DOI: http://dx.doi.org/10.14201/shhmo201537211234

\title{
DE LA NEGOCIACIÓN A LA COERCIÓN: LA RECAUDACIÓN DEL DONATIVO DE $1635^{1}$
}

\section{From Negotiation to Coercion: 1635 Donation's Revenue}

Francisco GIL MARTÍNEZ

Universidad de Almería

Correo-e: franciscogil@ual.es

RESUMEN: La mala situación económica de la hacienda regia y la ruptura bélica con Francia impulsaron a Felipe IV a requerir a sus súbditos un nuevo donativo. En este trabajo se estudian los métodos empleados por la corona para recaudar el donativo de 1635, en particular, las prácticas de los delegados regios que lo solicitaron individualmente a los súbditos castellanos. En dicha ocasión, el monarca no entregó dádivas a quienes le sirvieron con generosidad como había sucedido anteriormente, antes al contrario, sus ministros utilizaron diversas formas de coerción, desde amenazas y multas hasta penas de prisión, para forzar a la población a entregarles donativos. Se solicitó el donativo a todos estamentos, con especial énfasis a los grupos más acomodados, pues la cuantía de las aportaciones debía ir en función de la riqueza del vasallo.

Palabras clave: Donativo; Coerción; Fiscalidad.

ABSTRACT: The bad economic situation of the regal tax office and the war break up with France motivated Phillip IV to require from his subjects a new donation. In this paper the methods employed by the crown to raise the 1635 donation are studied, specifically the regals delegates practices

1. El presente estudio se ha realizado en el marco del Proyecto del Plan Nacional de $\mathrm{I}+\mathrm{D}$ «El poder del dinero. Dimensiones de la venalidad en los siglos XVII y xVIII (HAR2011-23105)», financiado por el Ministerio de Economía y Competitividad. 
that requested it individually to Castillian citizens. In said occasion, the monarch did not delivered gifts who served him with prodigiousness like happened before, rather the opposite, his ministers used diverse forms of coercion, from threatens and fines to prison sentences, in order to force population to give donations. Every social class was requested the donation, but with a special stress in the more well-off groups, given the quantity of the remittance had to be based on the vassal's wealthiness.

Key words: Donativo; Coercion; Fiscality; Taxation.

\section{INTRODUCCIÓN}

En este texto pretendemos ahondar en una de las figuras fiscales más peculiares del Antiguo Régimen, los donativos. Hasta ahora, los estudios al respecto han analizado la base teórica que sustentaba esta forma de recaudación pero, sobre todo, se han centrado en la cuantificación de los mismos con el fin de ponderar su importancia en el sistema fiscal castellano. A pesar de que estudiamos una práctica cuyo fin fundamental era allegar fondos a las arcas estatales, no lo hacemos desde un enfoque económico clásico, por lo que no encontrará el lector aquí las cantidades que se recaudaron en el donativo ni su importancia en las finanzas de la monarquía. Sí hallará en cambio un elemento complementario y, a nuestro juicio, fundamental para entender el fenómeno, como son los mecanismos institucionales y, especialmente, los métodos mediante los cuales se llevó a cabo la recaudación del donativo.

Tratamos por tanto de responder a las preguntas de quién, cómo y bajo qué circunstancias se solicitó el donativo, para lo cual nos hemos basado principalmente en documentación procedente del Archivo General de Simancas, en cuya sección de Consejo y Juntas de Hacienda se conserva la correspondencia entre los ministros reales que solicitaron el donativo y el secretario de la Junta encargada de gestionarlo, Juan Valero Díaz². A través de estas cartas se puede obtener un rico relato de las prácticas utilizadas por los comisionados para recaudar el donativo. Debemos hacer notar que a pesar de ser el canal de comunicación entre la Junta y sus delegados, la correspondencia era recibida únicamente por el secretario, quien presentaba después a la institución un resumen de lo escrito. Esto provocó que algunas de las cartas fueran más próximas al ámbito privado, ocupando el

2. En el Archivo General de Simancas [en adelante AGS] se encuentra la correspondencia del comisionado para Sevilla, Gaspar de Bracamonte, AGS, Consejo y Juntas de Hacienda [en adelante CJH], leg. 769; Valladolid, Juan Queipo de Llano y su delegado José de Frías Sandoval, AGS, CJH, leg. 763 y 769; Plasencia, Ciudad Rodrigo y Coria, Francisco Valcárcel, CJH, leg. 785. Las cartas de respuesta del secretario Juan Valero Díaz se encuentran en AGS, CJH, legs. 1729, 1753,1782 y 1789. 
secretario el papel de mediador entre la Junta y sus delegados ${ }^{3}$. Por medio de esa correspondencia los comisionados recibieron instrucciones, plantearon a la Junta los problemas que encontraban sobre el terreno y también consultaron la concesión de mercedes como recompensas a los donativos.

\section{DEFINICIÓN Y CARACTERÍSTICAS DE LOS DONATIVOS: LA TEORÍA}

Los continuos conflictos bélicos de la monarquía hispánica durante el siglo Xvir llevaron a la hacienda regia a una situación de quiebra. Sin embargo, las crecientes exigencias financieras de la guerra forzaron a Felipe IV a proseguir la vía de aumento de la carga tributaria iniciada por sus predecesores. Las tradicionales fuentes de financiación del Estado resultaban entonces insuficientes para mantener el enorme coste de los ejércitos, por lo que se recurrió a expedientes extraordinarios, ya experimentados en reinados anteriores. En este contexto se sitúan los diversos donativos solicitados por Felipe IV, monarca que, si bien no fue el primero en emplearlos ${ }^{4}$, sí fue quien con más profusión los solicitó a fin, sobre todo, de afrontar los cuantiosos gastos derivados de los conflictos bélicos de la monarquía 5 .

En los últimos años una serie de publicaciones han ahondado en estas figuras fiscales, que hasta hace poco apenas habían merecido más que una breve mención en los estudios generales. A pesar del interés suscitado, es un tema que todavía presenta algunas aristas y puntos oscuros a la investigación. La información con que contamos acerca de los donativos es muy limitada pues, de las nueve veces que Felipe IV requirió la ayuda de sus súbditos, únicamente se han realizado estudios particulares para los de 1625 y 1629. La evolución en cuanto a los métodos y formas de recaudar los donativos que hemos detectado, hace imposible generalizar los aspectos observados en estudios particulares, al menos hasta que contemos con trabajos específicos para cada petición.

La producción historiográfica en torno a los donativos se ha centrado hasta ahora, bien en sus características generales, siendo las principales referencias

3. Resultan especialmente interesantes las cartas de Luis Gudiel, pues trata con familiaridad al secretario y aporta muchos más datos que el resto de comisionados.

4. Las primeras referencias a la petición de donativos por parte del monarca datan de 1526 cuando Carlos V solicitó ayuda a sus súbditos para la guerra contra los turcos. Posteriormente, Felipe II y Felipe III recurrieron a este expediente en 1596-97 y 1604 respectivamente. Fortea PÉrez, J. I.: «Los donativos en la política fiscal de los Austrias (1625-1637): ¿ ¿ervicio o beneficio?» en RiBOT García, L. y Rosa, L. (eds.): Pensamiento y política económica en la época moderna. Madrid, 2000, pp. 31-76.

5. Felipe IV llegó a solicitar hasta nueve donativos durante su reinado, en 1625, 1629, 1632, $1635,1640,1649-51,1654,1655$ y 1664. 
Antonio Domínguez Ortiz, José Ignacio Fortea Pérez y Juan Eloy Gelabert ${ }^{6}$, bien en sus relación con los fueros territoriales ${ }^{7}$, así como en el estudio de donativos concretos, que tienen en las aportaciones de Ramón Lanza García su principal referente ${ }^{8}$. Por tanto, partiendo de los planteamientos que justificaban la petición de donativos, expuestos por José Ignacio Fortea Pérez ${ }^{9}$, hemos centrado nuestro estudio en tratar de esclarecer las prácticas de los comisionados durante la recaudación del más conflictivo de todos ellos, el solicitado en 1635. Los citados estudios realizados por Ramón Lanza García sobre el donativo de 1629, nos han permitido así mismo realizar interesantes comparaciones que no vienen sino a señalar las grandes diferencias entre unas y otras peticiones.

Los donativos, al menos en el plano teórico, funcionaban de forma diferente a la mayoría de las figuras fiscales de la época, pues constituían un ejercicio de bondad de los súbditos para con el príncipe, al que «voluntariamente» ayudaban. El debate, que llegó incluso a las Cortes, se encontraba en si los súbditos tenían la obligación moral, que no legal, de ayudar al soberano en la defensa de las causas justas. Suponían, por tanto, el establecimiento de una dialéctica directamente entre Rey y súbdito que prescindía de la mediación de las normas y leyes que regulaban

6. Domínguez Ortiz, A.: Política y Hacienda de Felipe IV. Madrid, Editorial de Derecho Financiero, 1960, pp. 297-314; Domínguez OrTiz, A.: «La desigualdad contributiva en Castilla durante el siglo XVII», en Instituciones y sociedad en la España de los Austrias. Barcelona, Ariel, 1985, pp. 97-145; Fortea Pérez, J. I.: «Los donativos en la política fiscal...», op. cit.; GelaberT GonzÁLEz, J. E.: La bolsa del rey: rey, reino y fisco en Castilla: (1598-1648). Barcelona, Grijalbo, 1997, pp. 222-226.

7. Truchuelo García, S.: «Privilegios y libertades fiscales: los donativos al monarca en los territorios vascos y Cataluña en el período altomoderno", Pedralbes: Revista d'historia moderna, 28, 2008, pp. 283-299; Truchuelo García, S.: «Donativos y exenciones: en torno a los servicios monetarios de las provincias vascas en el siglo xviI», comunicación presentada al IX Congreso Internacional de la Asociación Española de Historia Económica, Murcia, 2008, disponible en http:// www.um.es/ixcongresoaehe/pdfB2/Donativos.pdf [consultado el 21/04/2015].

8. Lanza García, R.: «El donativo de 1629 en la Andalucía Bética», Studia Historica. Historia Moderna, 32, 2010, pp. 179-227; LANZA García, R.: «El donativo de las guerras de Italia (1629): estudio del caso del Arzobispado de Toledo y la provincia de Guadalajara», Obradoiro de Historia Moderna, 19, 2010, pp. 125-159; LANZA GARCía, R.: «El donativo de 1629 en el distrito de Fernando Ramírez Fariñas» en Bilbao, L. M., Lanza, R., Álvarez, C., y Andrés, J. I. (eds.): IX Congreso Internacional de la Asociación Española de Historia Económica. Murcia, 2008, pp. 1-37. También es necesario destacar Fortea Pérez, J. I.: «El Donativo de 1625 en el realengo andaluz», en Marcos Martín, A. (ed.): Hacer Historia desde Simancas. Homenaje a José Luis Rodríguez de Diego. Valladolid, Junta de Castilla y León, 2011, pp. 317-338.

9. El artículo de Fortea Pérez, J. I.: «Los donativos en la política fiscal...», op. cit. resulta la principal referencia en cuanto a este tema, pues plantea las líneas fundamentales sobre las que han de discurrir posteriores investigaciones, si bien resulta de interés para el tema Fortea Pérez, J. I.: «Doctrinas y prácticas fiscales», en González Lopo, D. y López López, R. J. (eds.): Balance de la historiografía modernista: 1973-2001: Actas del VI Coloquio de Metodología Histórica Aplicada (Homenaje al profesor Antonio Eiras Roel). Santiago de Compostela, Xunta de Galicia, 2003, pp. 489-513. 
los derechos y deberes de ambas partes. Por consiguiente, hemos de entender los donativos dentro de la antropología política de la época, estrechamente relacionados con los conceptos de «gracia», «merced», «servicio» y «beneficio». No es nuestra intención extendernos sobre este complejo asunto acerca del que han corrido ríos de tinta ${ }^{10}$. Sin embargo, nos interesa destacar especialmente la naturaleza libre-léase voluntaria-que fundamentaba los donativos, pues entre dichos presupuestos teóricos y la realidad hubo, en el caso del donativo solicitado en 1635, una distancia enorme.

Los donativos no eran una obligación impuesta a los súbditos por parte del monarca, por lo que difícilmente podía vulnerar norma o fuero alguno. Este elemento resultó clave para el poder regio, que vio en ellos un potente instrumento de recaudación para gravar las fuentes de riqueza que hasta entonces habían escapado a su alcance. Los servicios de millones y los arbitrios utilizados por las oligarquías a nivel local habían drenado la maltrecha economía castellana y cada vez resultaban menos eficaces ${ }^{11}$. Prácticamente agotadas ya todas las vías de recaudación, las perennes necesidades bélicas imponían la búsqueda de nuevas vías por las que ingresar efectivo.

En primer lugar, la voluntariedad de los donativos evitaba que tuvieran que ser ratificados por las Cortes, lo que suponía saltarse el proceso de negociación con las ciudades que requerían los servicios de Millones. De la misma forma, las Cortes carecían de legitimidad para convertirse en mecanismo de control o en una instancia a la que recurrir durante el proceso de recaudación, lo que garantizaba una amplia libertad de movimientos al soberano. Como veremos más adelante, el caso de 1635 fue totalmente anómalo en este sentido, pues fueron las Cortes quienes propusieron y aprobaron el donativo como una vía de recaudación.

La búsqueda de una mayor implicación territorial en el esfuerzo tributario fue uno de los ejes principales del proyecto político del conde-duque de Olivares, en el que los donativos encajaban a la perfección, pues el establecimiento de una relación directa entre rey y súbdito también eludía los diferentes estatutos forales. Así pues, no tenemos constancia de donativos fuera de la corona de Castilla, pero sí que se extendieron por todos los territorios de esta, incluyendo las provincias vascas, Navarra, Canarias e incluso las Indias ${ }^{12}$. Aunque se llegaron a mandar

10. Sobre este particular Esteban Estríngana, A. (ed.): Servir al rey en la monarquía de los Austrias medios, fines y logros del servicio al soberano en los siglos XVI y XVII. Madrid, Sílex, 2012.

11. Marcos Martín, A.: «¿ Fue la fiscalidad regia un factor de crisis en la Castilla del siglo Xvir?» en Parker, G. (ed.): La crisis de la monarquía de Felipe IV. Madrid, 2006, pp. 173-254; Domínguez Ortiz, A.: Política y Hacienda de Felipe IV, op. cit., pp. 297-314

12. Truchuelo García, S.: «Privilegios y libertades fiscales...», op. cit. y Truchuelo García, S. «Donativos y exenciones... », op. cit; ; Porres MARIJUÁn, R.: «Las contribuciones vascas a la Hacienda Real en la Edad Moderna: algunos contrastes provinciales», Obradoiro de Historia Moderna, 19, 2010, pp. 87-124. 
las cédulas a Indias para que los virreyes se encargasen de la recaudación de los donativos, apenas si hay documentación al respecto en los archivos, lo que hace suponer que tuvo un alcance muy limitado en esos territorios o que finalmente no se llevó a cabo ${ }^{13}$.

De la misma forma, el establecimiento de una relación directa y voluntaria permitía la participación de los estamentos privilegiados, exentos de otro tipo de imposiciones, es decir la nobleza y el clero. Ambos estamentos tenían la obligación moral de ayudar al sostenimiento de la monarquía en periodo de guerra, la nobleza por estar sus privilegios fundamentados en su condición de bellatores medievales, y los religiosos por la justificación religiosa que hacía la monarquía de sus campañas. Llevar estas ideas a la práctica no resultaba sencillo por los grandes impedimentos que planteaban los propios nobles y eclesiásticos. Para vencer estas reticencias, Olivares desarrolló una serie de nuevas imposiciones, con la excusa de las necesidades bélicas ${ }^{14}$.

Según Fernández de Navarrete y Damián López de Haro, dos de los tratadistas estudiados por José Ignacio Fortea Pérez, tenían especial obligación de asistir con donativos los prelados eclesiásticos, la nobleza, los oficiales reales y, en general, todos aquellos con una posición económica desahogada ${ }^{15}$. Ambos tratadistas destacaron la participación de los más acomodados de la sociedad castellana, pues la ausencia de regulación en torno a los donativos permitía que la cuantía de los mismos variase en función de la riqueza de los donantes. Este elemento resultó fundamental, pues convertía a los donativos, al menos de forma teórica, en contribuciones proporcionales a la riqueza. No se trataba únicamente de hacer partícipes a todas las partes de la sociedad castellana del coste de las guerras, sino de implicarlas en la medida de sus posibilidades económicas.

Hasta aquí hemos destacado las características generales que convirtieron a los donativos en una solución idónea para aumentar y redistribuir el peso del gasto de la monarquía y sus conflictos bélicos. Sin embargo, la teoría que hemos presentado descansa sobre una base de cristal: la voluntariedad del donativo. Huelga decir que el discurso de los tratadistas que justificaban y alentaban a la participación en el donativo tuvo poco calado en la sociedad de la época. La forma en la que la monarquía recaudó los donativos resulta por tanto fundamental para aclarar si estos se ajustaron a las características que les atribuían los tratadistas, cuestión a la que tratamos de dar respuesta en este trabajo.

13. Las instrucciones para que los virreyes solicitasen el donativo se pueden encontrar en Archivo General de Indias, Indiferente General, leg. 2669.

14. Elliott, J. H.: El conde-duque de Olivares: el político en una época de decadencia. Barcelona, Crítica, 1998, p. 461.

15. Fortea Pérez, J. I.: «Los donativos en la política fiscal...», op. cit., p. 42. 


\section{LA RECAUDACIÓN DEL DONATIVO DE I635 $5^{\text {I6: }}$ LA ESTRUCTURA ADMINISTRATIVA}

La primera característica específica del donativo de 1635 que debemos señalar es que fue aprobado por las Cortes de Castilla como parte de un servicio de 9 millones de ducados en plata, de los cuales 5,5 debían ser obtenidos mediante un donativo. Este hecho ya supone una enorme contradicción con la teoría que sustentaba los donativos ${ }^{17}$. Tal y como hemos expuesto, los donativos debían ser otorgados de forma libre y voluntaria por los súbditos, por lo que las Cortes no jugaban ningún papel en el proceso, y mucho menos en determinar la cuantía que se iba a obtener. ¿Por qué motivo pues involucrar a las Cortes? La respuesta a esta pregunta radica en que iba a beneficiar tanto a la monarquía como a los propios procuradores. Por un lado, el monarca iba a obtener un elemento legitimador más para solicitar el donativo, pero, por otra parte, también iba a limitar las posibilidades por parte de la población de oponerse al mismo al contar con el apoyo de los procuradores. Por parte de las Cortes las ventajas de tal decisión no resultaban tan obvias, pero la fórmula adoptada les permitía ceder a las presiones del monarca al conceder un servicio de una elevada cuantía, y obtener así el favor del soberano. Aparentaban plegarse a los deseos del monarca cuando en realidad se estaban atribuyendo nuevas competencias en la representación del reino, a la vez que consolidaban sus atribuciones como principal mecanismo de financiación del Estado.

En consecuencia, el donativo de 1635, lejos de seguir la línea marcada en anteriores peticiones, iba a convertirse en un servicio al mismo nivel que otros arbitrios extraordinarios aprobados por los procuradores castellanos. Aprovechando la legitimación que le otorgaban los procuradores, la monarquía puso en marcha una serie de mecanismos coercitivos para garantizar la recaudación. Como demostramos más adelante, el donativo de 1635 no fue por tanto una contribución voluntaria sino que, bajo el nombre de donativo, se trató de un nuevo servicio de los contribuyentes castellanos. A pesar de que ni la concesión de las Cortes ni las formas de recaudación eran las propias de un donativo, la monarquía siguió empleando el término para poder forzar a los estamentos privilegiados a contribuir de forma significativa.

Los donativos eran solicitados por el monarca a sus súbditos cuando lo estimaba necesario, por lo que no existía una estructura institucional estable para la recaudación de los mismos. A pesar de ser una medida extraordinaria y puntual, la frecuencia con que se dieron durante el reinado de Felipe IV creó y consolidó una

16. El proceso empezó en los últimos meses de 1635, aunque el grueso de las peticiones se realizó en 1636, por lo que también es frecuente que se encuentre en la documentación con esta última fecha como referencia.

17. Domínguez Ortiz, A.: «La desigualdad contributiva en Castilla...», op. cit., p. 112. 
serie de mecanismos institucionales para este fin. El primero de ellos fue la creación de una Junta, institución tan del gusto del conde-duque de Olivares debido a la facilidad para controlarla, formada por el propio valido y fundamentalmente por consejeros de Castilla así como por miembros de otras altas instancias de gobierno de la monarquía ${ }^{18}$. Teóricamente se debía crear una junta para cada donativo pero, en la práctica, los largos plazos para la cobranza de las cuotas de los donativos, así como la constante sucesión de peticiones, mantuvieron durante la década de 1630 una única Junta en constante funcionamiento, en la cual ingresaban nuevos miembros con cada petición de donativo, y que se encargaba de gestionar tanto la recaudación de los nuevos donativos como la cobranza de los antiguos. A la altura de 1635 presidía la Junta el conde-duque de Olivares, y formaban parte de ella Fernando de Llano y Valdés, arzobispo de Granada y gobernador del Consejo de Castilla; García de Haro y Avellaneda, conde de Castrillo y consejero de Estado, Justicia e Indias; José González, consejero de la Cámara de Castilla, Justicia y Cruzada; y Miguel de Ipeñarrieta, consejero de Hacienda. Todos ellos pertenecían al círculo más cercano a Olivares y con intereses coincidentes con los del valido. El secretario, pieza clave en el funcionamiento de la Junta, fue Juan Valero Díaz, y el contador Martín de Medina Laso de la Vega ${ }^{19}$. Al haber sido el donativo de 1635 aprobado por las Cortes, se crearon dos plazas de consejeros de la Junta para procuradores en Cortes, los cuales debían velar por el correcto funcionamiento del proceso. Los elegidos fueron Martín de Guzmán, procurador por Zamora, y Bernardo de Ribera por Sevilla.

Esta Junta era la encargada de elegir y nombrar a los comisionados de entre los miembros del Consejo de Castilla y de las Chancillerías y Audiencias, quienes debían desplazarse personalmente para recaudar el donativo. Los colaboradores más estrechos de Olivares permanecieron en la Corte, controlando las principales instancias de poder, mientras que la tarea de recaudar el donativo recayó principalmente en aquellos consejeros peor relacionados en las altas esferas pues, de hecho, ninguno de los camaristas hubo de desplazarse fuera de Madrid para recaudar el donativo. En las Chancillerías y Audiencias el criterio de elección fue precisamente el contrario, elegir a quienes tenían contactos en la Corte, pues las comisiones los ponían por encima del resto de miembros del tribunal. Es el caso de Alonso Ramírez de Prado, oidor de Granada y comisionado en el obispado

18. Baltar Rodríguez, J. F.: Las juntas de gobierno de la monarquia hispánica: (siglo XVI-XVII). Madrid, Centro de Estudios Políticos y Constitucionales, 1998, pp. 282-288. SÁnchez González, D. M.: El deber de consejo en el Estado Moderno: las juntas «ad hoc» en España (1474-1665). Madrid, Polifemo, 1993, p. 279.

19. AGS, CJH, lib. 156. Citado también en Fortea Pérez, J. I.: «Los donativos en la política fiscal...», op. cit., p. 55. 
de Cádiz, cuyo hermano, Lorenzo, era miembro de varias Juntas, además de ser consejero de Indias.

La Junta dividió el territorio castellano en distritos, que generalmente coincidían con las diócesis, y asignó cada uno a un comisionado. La Junta era la institución que daba las instrucciones generales a los comisionados y quien mantenía el contacto con estos mientras se encontrasen fuera de la Corte, comunicándoles las decisiones tomadas y resolviendo las dudas que se les planteasen. La Junta también llevaba la contabilidad general del donativo, ejecutaba los cobros y libraba las cantidades para los gastos de la Monarquía.

Los comisionados dependían en primera instancia de la Junta, que era quien les había otorgado la cédula de comisión para recaudar el donativo, y por tanto la institución que controlaba sus actuaciones. No obstante, para la concesión de mercedes como agradecimiento del monarca por los donativos concedidos, se requería la aprobación de la Cámara de Castilla, por lo que era esta quien controlaba realmente el proceso de ventas de patrimonio regio encubiertas bajo el nombre de «donativo». Los propios camaristas, destacando entre ellos a José González, Antonio de Alarcón y Antonio de Contreras, habían recibido comisiones particulares para beneficiar mercedes, especialmente de ámbito local ${ }^{20}$, por lo que entraban a competir desde la Corte con las que podían ofrecer los ministros del donativo sobre el terreno. Los camaristas, al verse perjudicados en sus comisiones, utilizaron su posición predominante en la Cámara de Castilla para entorpecer los trámites en la concesión de mercedes en las que ellos no habían participado ${ }^{21}$. Retrasar las diligencias e incluso rechazar los acuerdos a los que habían llegado los comisionados del donativo con los compradores eran fórmulas empleadas con frecuencia por la Cámara. Sin dádivas con las que gratificar las grandes contribuciones al donativo, los comisionados perdieron poder negociador, pues su credibilidad quedaba en tela de juicio cuando las negociaciones se torcían ${ }^{22}$. La falta de coordinación con las instituciones centrales llegó a los comisionados a sentirse abandonados sin recursos para llevar a cabo la tarea que les había sido encomendada, e incluso trataron de sortear a la Cámara escribiendo directamente al monarca o al conde-duque y a sus colaboradores más cercanos, caso del protonotario de Aragón ${ }^{23}$.

Sin embargo, además de la capacidad de conceder y tramitar determinados tipos de mercedes, los comisionados recibían otros poderes pues, en las áreas territoriales que les eran asignadas, se convertían en la máxima autoridad en su materia, para

20. Domínguez Ortiz, A.: Política y Hacienda de Felipe IV, op. cit., p. 61.

21. Carta de Luis Gudiel a Juan Valero de 23 de enero de 1636. AGS, CJH, 754.

22. Carta de Luis Gudiel a Juan Valero de 1 de enero de 1636. AGS, CJH, 754.

23. Carta de Luis Gudiel a Su Majestad de 1 de enero de 1636. AGS, CJH, 754. 
lo cual recibían jurisdicción privativa, lo que los situaba por encima de cuantas autoridades locales existiesen, incluidas las propias Chancillerías ${ }^{24}$. No fueron infrecuentes, como detallaremos más adelante, los conflictos entre comisionados y Audiencias y Chancillerías, especialmente cuando los primeros solicitaron a los jueces locales un cuantioso donativo. El método de los comisionados ya se había ensayado en 1629 cuando, tras obtener unos pobres resultados por parte de los corregidores en los que originalmente había recaído la responsabilidad de solicitar el donativo, la corona decidió enviar a ministros con poderes especiales. Sin embargo, tal y como ha expuesto Ramón Lanza en sus trabajos, el donativo canalizaba «las peticiones que en circunstancias normales los individuos y las corporaciones habrían dirigido a los consejos de la monarquía» ${ }^{25}$. El donativo era pues una forma de alcanzar la gracia regia por medio del servicio al monarca en forma de dinero. El cambio respecto a 1635 fue radical, pues en vez de «estimular» la generosidad de los súbditos mediante la gracia, se utilizó la coerción para forzarlos a colaborar. Como autoridad en el territorio, la única instancia de apelación que podía limitar sus actuaciones era la Junta del Donativo o el Consejo de Castilla, instituciones ambas con sede en Madrid, por lo que la distancia hacía que los comisionados no tuviesen que responder de sus negociaciones ante sus superiores hasta pasados días e incluso meses. A pesar del amplio margen con que contaban estos ministros, en algún caso extremo llegó a intervenir la Junta para reprender la actuación de algún comisionado por exceso de celo en su tarea.

Los comisionados contaban a su vez con ayuda para gestionar el distrito que les había sido asignado. Esta ayuda procedía principalmente de los cargos auxiliares que podían nombrar, tales como depositarios o ejecutores, a los que trataban de elegir de entre las autoridades locales. Supuestamente debían visitar todos los lugares del distrito que les correspondiese pero, como escribía Gaspar de Bracamonte, este procedimiento provocaba que «se pierda lo más sustancial, que es la prontitud» ${ }^{26}$, por lo que los comisionados solicitaron licencia a la Junta para delegar parte de sus poderes en otros ministros que visitasen las zonas menos pobladas y de más difícil acceso.

Los delegados regios se apoyaron en los ministros de las Chancillerías y Audiencias y en los corregidores, especialmente en las ciudades de mayor tamaño donde era necesario realizar una subdivisión en parroquias, que eran asignadas a los

24. CÁRCELES DE GEA, B.: «Del juez de comisión al comisario real (1632-1643). El fraude fiscal como agente del "gobierno económic"», Studia Historica. Historia Moderna, 13, 1995, pp. 155-175. Gómez González, I.: «Más allá de la colegialidad. Una aproximación al juez de comisión en la España del Antiguo Régimen», Chronica Nova, 37, 2011, pp. 21-40.

25. Lanza García, R.: «El donativo de 1629 ...», op. cit., p. 7. 754.

26. Carta de Gaspar de Bracamonte a la Junta del Donativo del 28 de enero de 1636, AGS, CJH, 
colaboradores, mientras que de las oligarquías urbanas se ocupaban en exclusiva los comisionados. En general, los corregidores, aunque reticentes por tener que enfrentarse a las oligarquías locales, acataron las órdenes de los comisionados.

Esta organización ya se había ensayado previamente en el donativo de 1629, también llamado donativo de las guerras de Italia, pues fue el primero en el que se despacharon funcionarios reales investidos de autoridad, sentando el precedente del de 1635, pues en los anteriores habían sido las autoridades locales las encargadas de solicitarlo a los vecinos ${ }^{27}$. Mientras que en 1629 los donativos fueron la vía que permitió canalizar las peticiones de mercedes por parte de los súbditos al monarca, en 1635 esta fórmula apenas se practicó a causa de varios inconvenientes. En primer lugar, el proceso administrativo por el que las mercedes eran concedidas y aprobadas tenía un cuello de botella en la Cámara de Castilla. La lentitud de esta vía de obtención de mercedes contrastaba notablemente con la eficacia administrativa de otros canales existentes creados para ello por Olivares. Nos referimos a las múltiples Juntas, comisionados especiales, y sus respectivos delegados, algunos incluso miembros de la propia Cámara de Castilla, que enajenaban todo tipo de mercedes creando un caótico mercado en el que la corona se hacía la competencia a sí misma. Tal mercado ofrecía aún mayores problemas, pues los potenciales compradores debían desplazarse a la Corte para conseguir sus objetivos, lo que encarecía el proceso para el comprador y disminuía el beneficio para la Real Hacienda por la competencia de instituciones. El exceso de oferta en la Corte provocaba que los ingresos por las diferentes vías de enajenación, ya fuesen los consejos, comisionados o juntas, fuesen proporcionalmente menores. No tardaron las instituciones y los comisionados encargados de las ventas en percatarse de que desplazándose directamente a los lugares aumentaba el número de posibles compradores, lo que les permitía incrementar tanto el número de ventas como la cuantía de las mismas. La competencia no solo se daba ya en la Corte sino también en las provincias con el consiguiente perjuicio para el fisco, pues allí llegaron a encontrarse comisionados para el donativo con otros agentes reales que ofrecían mercedes a cambio de servicios pecuniarios. El sistema resultaba tan caótico que los mismos comisionados que recaudaban el donativo recibían también comisiones por parte de otras instituciones en un tibio intento de racionalizar el sistema.

Así exponía Luis Gudiel, comisionado del donativo en Granada (quien también había recibido poderes para vender las tierras de realengo improductivas tras la expulsión de los moriscos y negociar exenciones de lugares ${ }^{28}$ ), el conflicto provocado con

27. Espejo Hinojosa, C.: «Preliminares en Madrid y su jurisdicción del Donativo de 1625», Revista de la Biblioteca, Archivo y Museo de la Comunidad de Madrid, 8, 1925, pp. 553-559.

28. Carta de Luis Gudiel a Juan Valero de 18 de diciembre de 1635. AGS, CJH, 754. Su omisión para la venta de baldíos provocó numerosos conflictos. Domínguez OrTiz, A.: «La comisión de D. Luis Gudiel para la venta de baldíos de Andalucía», en Congreso de historia rural: siglos XV-XIX: 
el fiscal de la Chancillería Diego de Angulo, en quien José González, hombre de confianza de Olivares, había delegado sus comisiones para enajenar gracias por el Consejo de Castilla:

Veo destruir el servicio del Rey en que las materias de las gracias y ventas de oficios corran por diferentes manos porque con eso los merchantes acuden siempre a quien le hace mayor barato. El señor José González ha dado en subdelegar sus comisiones en un mozuelo que está aquí fiscal de esta Audiencia [...] y es mi mona y mi arrendajo y mi sombra y no hay cosa que yo haga que no la quiera hacer también en virtud de quien le conforta [...] suplicándole a la Junta se ponga remedio en ello que no parece puesto en razón ni tiene conveniencia para el servicio de Su Majestad que mientras yo estuviere aquí corran estas cosas por diferentes manos y también sabré yo cumplir las órdenes que me enviare el señor José González sirviéndose de enviármelas como lo hace don Diego de Angulo ${ }^{29}$.

Gudiel llegó a plantear que los comisionados para el donativo, en virtud de su elevado rango en la administración, asumiesen también todas las comisiones para la venta de mercedes en el distrito que les correspondía, remitiendo por cuenta aparte los caudales a las instituciones pertinentes ${ }^{30}$. El objetivo era eliminar la competencia, facilitar la tarea de contactar con los compradores y evaluar sobre el terreno las ofertas recibidas. La propuesta no llegó a realizarse, por concentrar demasiado poder en los comisionados, si bien se realizaron algunos esfuerzos al aunar comisiones por diferentes instituciones en una misma persona.

En las instrucciones a los comisionados en 1635 se puede advertir el cambio radical que se produjo respecto a anteriores donativos, pues se hizo especial hincapié en la jurisdicción privativa que tenían los comisionados, inhibiendo al resto de tribunales ${ }^{31}$. El papel fundamental de los comisionados iba a ser presionar a los súbditos para obtener fundamentalmente ingresos de los más acaudalados, siendo las cédulas que recibieron específicas sobre este punto, pues se les indicaba que «si no pudiesen reducirlos a lo que fuese justo, podrá valerse de los medios que le pareciesen menos ruidosos, y cuando nada de esto valga, les mandará por un auto que dentro de uno o dos días a lo más largo, y con las penas que le pareciese» ${ }^{32}$. Por tanto, se planteaba, ya desde el inicio, la coerción como principal mecanismo

actas del coloquio celebrado en Madrid, Segovia y Toledo del 13 al 16 de octubre de 1981. Madrid, Universidad Complutense, 1984, pp. 511-522.

29. Carta de Luis Gudiel a Juan Valero Díaz del 28 de enero de 1636, AGS, CJH 754. Se conserva también el testimonio del propio Diego de Angulo en AGS, CJH, 763. 754.

30. Carta de Luis Gudiel al conde-duque de Olivares de 19 de febrero de 1636. AGS, CJH

31. Biblioteca Nacional de España, V.E., 50/23.

32. Domínguez Ortiz, A.: «La desigualdad contributiva en Castilla...», op. cit., p. 113. 
para recaudar el donativo, si bien, como la propia cédula exponía, todo debía hacerse de forma reservada evitando en la medida de lo posible los escándalos.

Uno de los elementos claves en el uso de la coerción fue la urgencia con la que se necesitaba el dinero. El conflicto con Francia había estallado y no solo era necesario el dinero sino también recuperar a los delegados regios dispersos por la geografía. La Junta se marcó el objetivo de acabar la recaudación del donativo en $1635^{33}$, pero tan ambicioso propósito no llegó a lograrse, pues solicitar la contribución de forma individual requería mucho más tiempo, hasta el punto de que en 1637 todavía quedaban varios comisionados por acabar su tarea.

En las zonas urbanas de más movimiento económico se situaron asientos sobre las obligaciones de pago recogidas por los comisionados. En Sevilla, por ejemplo, lo recaudado del donativo era utilizado directamente para pagar uno de los asientos firmados por Bartolomé Spínola ${ }^{34}$, mientras que en Málaga era el bolsillo de Lelio Branchio el destino final del dinero. Las consignaciones hechas sobre el donativo fueron en 1637 de 249.448 .620 maravedís y en 1638 descendieron hasta los 187.500 .000 , constituyendo alrededor del $5 \%$ de las consignaciones totales de la monarquía en esos años ${ }^{35}$. Sin embargo, lo recaudado por el donativo debió ser una cantidad mayor por varios motivos. Por una parte, no contamos con datos disponibles para 1636, año en el que los ingresos debieron de ser mayores al abarcar la mayor parte de la recaudación directa. Además, desconocemos las cantidades libradas directamente por la Junta para gastos concretos, por lo que las estimaciones al respecto resultan poco ajustadas.

\section{LA ACTUACIÓN DE LOS COMISIONADOS}

La instrucción que recibieron los comisionados en 1635 junto con las cédulas para desarrollar su labor era bastante explícita en los métodos que debían emplear ${ }^{36}$. Los comisionados recibieron poder para conceder facultades, arbitrios y medios con los que facilitar el pago de los donativos, pero también censos sobre los mayorazgos, e incluso indultos, si bien hicieron escaso uso de estas facultades. En esta primera instrucción, que posteriormente sería modificada, los comisionados debían solicitar el donativo tanto a los particulares como a las comunidades, prefiriendo siempre a estas últimas, pues era un método de recaudación más rápido, además de que evitaba multitud de conflictos. No obstante, las negativas consecuencias de la recaudación por comunidades llevaron a la monarquía a inclinarse por solicitar

33. Carta de Luis Gudiel a Juan Valero Díaz del 12 de agosto de 1636. CJH, 754.

34. Casta de Gaspar de Bracamonte a Juan Valero de 17 de febrero de 1637. AGS, CJH, 769.

35. Marcos Martín, A. «¿Fue la fiscalidad regia un factor de crisis...», op. cit., p. 222.

36. Biblioteca Nacional de España, V.E., 50/23. 
el donativo individualmente, decretando a los comisionados que no aceptasen los ofrecimientos de las comunidades ${ }^{37}$.

Mediante la negociación con las élites locales se habían logrado grandes cantidades en 1629, sin embargo, los donativos ofrecidos por las comunidades procedían generalmente de sisas, propios y arbitrios similares, concedidos en muchos casos por los propios comisionados para que los municipios pudiesen afrontar la nueva carga. Los más afectados por estas medidas tomadas por los cabildos eran invariablemente los grupos sociales con menores ingresos, cuyo sustento dependía en mayor medida de los bienes básicos sobre los que se establecían las sisas y del libre uso de baldíos y tierras comunales. Así pues, las élites utilizaban su posición de poder local para hacer recaer el peso de los servicios sobre el resto de la población.

Para que el donativo fuese proporcional a la riqueza de los súbditos debía solicitarse individualmente, pues de lo contrario las élites utilizarían su papel de mediadoras entre la corona y el pueblo llano en su propio beneficio, cual había sucedido en anteriores ocasiones. No se trata de un caso excepcional, pues casos similares, en los que figuras fiscales destinadas a gravar de forma directa a los grupos privilegiados acababan desvirtuándose y convirtiéndose en tributos indirectos que recaían sobre los más desprotegidos, han sido ya señalados por investigadores de la talla de Felipe Ruiz Martín ${ }^{38}$.

Además, debido a la delicada situación financiera de los municipios, los miembros de la Junta sabían que iba a ser difícil realizar la cobranza de las cantidades ofrecidas, y que lo más probable era que se alargase durante años e incluso décadas ${ }^{39}$. Sin embargo la urgencia con la que se necesitaba el dinero era inmediata, la guerra con Francia acababa de estallar y levantar y mantener los ejércitos de la monarquía era terriblemente costoso para la maltratada hacienda regia, por lo que se decidió acudir al método más directo posible, haciendo especial hincapié en la rápida cobranza de los donativos. El método personal, a pesar de llevar más tiempo para recaudar los ofrecimientos en cada localidad, ofrecía mayores cantidades en efectivo y unos plazos de cobranza generalmente más cortos que los negociados por los cabildos, que tardaban años en pagar. Así pues, la recaudación de forma

37. Fortea Pérez, J. I.: «Los donativos en la política fiscal...», op. cit., p. 53.

38. Ruiz Martín, F.: «Procedimientos crediticios para la recaudación de los tributos fiscales en las ciudades castellanas durante los siglos xvi y xvir: el caso de Valladolid» en OTAzu y LLANA, A. (ed.): Actas del I Coloquio Internacional de Historia Económica. Dinero y Crédito (siglos XVI al XIX). Madrid, 1978, pp. 37-47.

39. A ese respecto es un buen ejemplo lo sucedido con el donativo de 1629. Quintanilla GonzÁlez, R.: «¿Obejo, Córdoba y otras villas de su jurisdicción pagaron el donativo de 1629?», Crónica de Córdoba y sus pueblos, 16, 2009, pp. 263-330. 
individual, aunque ocupaba a los ministros durante más tiempo, permitía a la monarquía disponer del dinero en efectivo un plazo menor.

A pesar de las instrucciones expresas de pedir el donativo a particulares, los comisionados recibieron frecuentes ofrecimientos de los cabildos con la intención de evitar que solicitasen el donativo individualmente. De igual forma, los comisionados tenían interés en evitar los conflictos y acabar con rapidez la recaudación del donativo para volver a la Corte, por lo que solicitaron constantemente a la Junta que se les permitiese aceptar donativos de comunidades. Las negativas de la Junta obligaron a los comisionados a tomar la difícil alternativa de solicitar el donativo de forma individual.

Uno de los ejemplos más interesantes de la disyuntiva entre donativos de comunidades o individuales lo encontramos en la comisión de Luis Gudiel en Granada. Allí el comisionado, tras largas negociaciones con las facciones que controlaban el cabildo, consiguió el apoyo de parte del mismo al aprobar-por veintidós votos de los treinta y seis caballeros veinticuatros de la ciudad- un donativo de 200.000 ducados $^{40}$. Gudiel había atraído a los caballeros con la promesa de mercedes, en concreto les había ofrecido seis hábitos de las órdenes militares ${ }^{41}$. El comisionado había centrado su atención en las familias que controlaban más de una regiduría, como era el caso de los veinticuatros Álvaro y Luis Cepeda y Ayala, padre e hijo, que contribuyeron a allanar las posiciones de varios miembros del cabildo ${ }^{42}$. Sin embargo, tanto las negociaciones como la votación del cabildo fueron en vano, pues la Junta se negó a aceptar el servicio por parte de la ciudad y ordenó al comisionado seguir las instrucciones y solicitar el donativo de forma individual.

Lejos del fácil trámite que habría supuesto negociar con los veinticuatros, Gudiel iba a tener que recorrer la ciudad entera, parroquia a parroquia, tratando con todos los vecinos. Para no perder el apoyo que había conseguido entre los veinticuatros Gudiel trató de renegociar las mercedes ofrecidas pero ya a cambio de sustanciosos donativos personales. Sin embargo, las mercedes eran concedidas por la Cámara de Castilla y, a los inconvenientes que hemos señalado más arriba, venía a sumarse la falta de confianza en las promesas del comisionado, pues en Granada recordaban todavía lo sucedido en el anterior donativo. En 1629 el comisionado Juan Chumacero había utilizado una estrategia similar a la de Gudiel, ofreciendo mercedes a los miembros del cabildo a cambio de la aprobación de un cuantioso donativo. Sin embargo, el cabildo no actuó según lo acordado y acabó votando una cantidad menor de la pactada, por lo que

40. Carta de Luis Gudiel a Juan Valero de 23 de diciembre de 1635. AGS, CJH, 754.

41. Carta de Luis Gudiel a Juan Valero de 18 de diciembre de 1635. AGS, CJH, 754. 754.

42. Carta de Luis Gudiel al conde-duque de Olivares de 31 de diciembre de 1635. AGS, CJH, 
Chumacero, notablemente molesto, abandonó la ciudad y como forma de castigo se negó a expedir las mercedes pactadas ${ }^{43}$.

Los veinticuatros granadinos tenían presente aquella actuación de Chumacero, por lo que en 1636 se negaron a otorgar escritura de pago alguna hasta verse con las mercedes prometidas. Cuando el trámite en la Corte de los hábitos prometidos tardó más tiempo del previsto, pues el proceso venía durando cerca de un año, la credibilidad del comisionado entre la oligarquía prácticamente desapareció y muy pocas de las mercedes negociadas llegaron a materializarse. De los seis hábitos de las órdenes militares que con tanta insistencia había solicitado Gudiel a la Junta no llegó ninguno a sus manos, si bien trató de premiar a quienes le habían ayudado en su tarea mediante la elaboración de memoriales en los que solicitaba que el monarca les concediese las gracias que pedían. En los casos más destacados, como el anteriormente mencionado de la familia Cepeda y Ayala, el comisionado trató de ponerlos en contacto directamente con las instituciones que, en la Corte, y previo pago, podrían concederles las mercedes ${ }^{44}$.

Los comisionados podían conceder directamente facultades para tomar censos sobre mayorazgos, indultos por pequeños delitos y gracias similares, pero las mercedes de mayor valor, tales como oficios de gobierno, hábitos u otros honores, quedaban fuera de su alcance, sirviendo únicamente como enlace con la Junta y en último término la Cámara de Castilla. Por tanto, los beneficios que podían conceder a las oligarquías para ganar su colaboración eran escasos o de poco interés para estas, restringiéndose el margen de negociación respecto a anteriores donativos. En este sentido las quejas de los comisionados a la Junta se repetían en la mayoría de los distritos. Desde Sevilla escribía Gaspar de Bracamonte a la Junta que «las gracias que de aquí se envían no se despachan, con lo cual son poquísimos los que se ofrecen» ${ }^{45}$.

Si el donativo empezó en el reino de Granada con unas élites urbanas haciendo grandes ofrecimientos el final sería muy diferente, con multitud de cabildos planteando quejas al Consejo de Castilla por los métodos empleados para recaudar el donativo. La lluvia de mercedes, que en peticiones anteriores habían derramado los comisionados sobre quienes se habían alargado con sus donativos, había desaparecido también. En su lugar, la corona, utilizó la coerción para obtener una nueva contribución de sus súbditos.

43. Carta de Luis Gudiel a Juan Valero de 18 de diciembre de 1635. AGS, CJH, 754.

44. Desconocemos cuál era la merced que pretendía esta familia en pleno proceso de ascenso social por la que estaban dispuestos a servir hasta 10.000 ducados según Gudiel. Carta de Luis Gudiel a Juan Valero de 1 de enero de 1635. AGS, CJH, 754.

45. AGS, CJH, 769, carta de Gaspar de Bracamonte a la Junta del Donativo de 17 de febrero de 1637. 
Además, mientras que en anteriores ocasiones la participación era voluntaria, en 1635 se le solicitó el donativo toda la población. Para ello se recomendó a los comisionados que utilizasen censos, padrones, libros de alcabalas, registros parroquiales y, en general, cualquier registro de población que encontrasen. Los comisionados recurrieron con mayor frecuencia a los corregidores para localizar estos documentos, aunque también acudieron a los cabildos, tanto civiles como eclesiásticos. Con los registros en la mano, los comisionados o sus delegados llamaban a los vecinos de forma individual para solicitarles el donativo. Hubo quienes trataron de ausentarse de los lugares cuando preveían que iban a ser llamados, lo cual no evitaba el proceso, pues eran anotados por el comisionado para solicitarles más tarde el donativo. Ya ante los ministros enviados para la cobranza, abundaron los que trataron de excusarse por diferentes motivos. De quienes argumentaban ser pobres, los ministros tomaban lo ofrecido sin ejercer más presión que la de su mera presencia-bastante imponente de por sí- tal y como se les recomendaba en la instrucción. La creciente carga tributaria que sufría el campesinado castellano provocaba que, en palabras de uno de los propios comisionados, «si en este tiempo se les apretara más [...] pudieran suceder algunos disturbios» ${ }^{46}$.

La actividad de los comisionados se centraba en los núcleos de población más grandes, utilizando a otros ministros reales así como a las instituciones locales para recaudar el donativo en las villas y aldeas rurales con menos vecinos, si bien los métodos apenas sufrían modificaciones cuando eran los subdelegados los encargados de la recaudación. Así exponía Luis Gudiel la forma en que había dispuesto la recaudación de aldeas y villas de escasa población de la tierra de Málaga, mientras él permanecía en las zonas más pobladas y ricas:

Aún entre los pobres de los dichos lugares hay desigualdad de caudales, y no es razón que sirvan unos con tanto como otros, he prevenido este inconveniente proveyendo un auto general que he ido entregando a los alcaldes de los dichos lugares con quienes me he concertado para que cada uno de sus vecinos conforme a sus caudales les señalen la cantidad con que pareciere deben contribuir y que si algunos no lo quisieren hacer les notifiquen se vengan a ver conmigo dentro de tres o cuatro días pena de diez o veinte ducados. Con lo cual todos se han allanado y aquietado sin recurrir a mi ninguno de los lugares cortos de la jurisdicción de esta ciudad y de la de Málaga, Vélez y Loja con quienes hasta aquí he aguardado este estilo.

Sin embargo, aquellos que contaban con una posición más desahogada fueron los principales objetivos de los comisionados, especialmente en los casos en los que trataron de eximirse o, en su defecto, de aportar donativos de escasa cuantía en relación a sus haciendas. Para determinar la cuantía del donativo que cada

46. AGS, CJH, 754, carta de Luis Gudiel a Juan Valero de 20 de mayo de 1636. 
contribuyente debía aportar los comisionados hacían averiguaciones sobre la hacienda de los más ricos, fundamentalmente a partir de testimonios de vecinos recogidos en secreto. A partir de varias informaciones de este tipo el comisionado se formaba una idea de la fortuna de los individuos más destacados para después solicitarles un donativo acorde a dichas averiguaciones. Por supuesto los testimonios secretos daban pie a exageraciones, engaños y, sobre todo, constituían un potente catalizador de conflictos internos en las localidades, lo que resultaba útil al comisionado, pues era preferible una oligarquía dividida y enfrentada entre sí a un grupo cohesionado planteando impedimentos a la recaudación del donativo. La ciudad de Antequera, por ejemplo, pidió al comisionado que hiciese merced del «consumo de las preeminencias del oficio de alcaide sobre el que ha habido tantos pleitos e inquietudes en los bandos de esta ciudad». Para obtener esta gracia, la ciudad ofrecía un donativo por la enorme cifra de 36.000 ducados $^{47}$. Aunque ni se aceptó el donativo ni se concedió la gracia, la cifra da una idea de las facilidades que se le planteaban a los comisionados cuando las oligarquías se hallaban divididas en facciones contrarias.

El modo de proceder de los comisionados ante quienes rechazaban otorgar donativos o realizaban ofrecimientos cortos era negarse a aceptar las cantidades, para después exponerles la situación de la monarquía y tratar de convencerles de que era su deber como católicos y súbditos del monarca contribuir a la defensa de la monarquía. Si este primer procedimiento resultaba en balde se recurría a la coerción verbal. Se les explicaba entonces la autoridad con la que contaban y se les amenazaba con informar de su oposición a la Junta del Donativo mediante los «votos secretos» en los que detallarían la fortuna que les suponían, por lo que previsiblemente les demandarían una cantidad muy superior a la que en el momento se les solicitaba. Si perseveraban en su negativa se les llegaba a amenazar con multas e incluso la prisión inmediata y el embargo de sus bienes.

En los casos de resistencia aislada de algunos individuos, los comisionados se limitaban a enviar los «votos secretos» a la Junta y a esperar que esta determinase lo que debían ofrecer como donativo. Pronto la documentación desbordó a la institución, por lo que en algunos casos los recalcitrantes no llegaron a colaborar, si bien en otros acabaron contribuyendo con cantidades sustanciosas. Cuando la oposición a los comisionados era generalizada, lo que sucedió en numerosas localidades, estos se veían abocados a emplear medidas más drásticas, ordenando a los alguaciles mantener bajo custodia en sus domicilios a los que se negaban o, en los casos más graves, trasladarlos a dependencias municipales. Algunos comisionados llegaron a arrestar a cabildos enteros, exigiendo para su puesta en libertad generosas contribuciones al donativo. Es el caso de Francisco Valcárcel,

47. AGS, CJH, 754, carta de Luis Gudiel a Juan Valero de 11 de junio de 1636. 
quien ordenó en septiembre de 1637 al corregidor Diego Hurtado de Mendoza apresar a todo el cabildo de Ciudad Rodrigo por negarse a colaborar en la cobranza de las cantidades ofrecidas bajo presión por los vecinos de la villa ${ }^{48}$. Los regidores llegaron incluso a celebrar las reuniones del concejo en la prisión, cediendo allí a las presiones del comisionado ${ }^{49}$. Además de la privación de libertad, los comisionados tenían también potestad para embargar los bienes de los obstinados en no participar, si bien por las dificultades técnicas y por lo extremo de la medida esta circunstancia no se dio salvo en casos excepcionales. Estas situaciones fueron las que más quejas generaron ante la Junta del Donativo que, al contrario que en 1629 , cuando denegaban los ofrecimientos realizados bajo coerción ${ }^{50}$, se limitó a dejar hacer a los comisionados si bien les recomendaba utilizar métodos menos conflictivos.

Las Chancillerías y Audiencias, que debían servir de apoyo a los comisionados, fueron en algunos casos elementos de resistencia al donativo. La Chancillería de Valladolid fue en este sentido la más conflictiva, pues los caballeros con mayores haciendas de la ciudad hicieron ofrecimientos muy cortos al comisionado Juan Queipo de Llano, que hizo uso de sus poderes para embargarles los bienes. El presidente de la Chancillería se puso de parte de los caballeros, aunque trató de mediar entre ellos y el comisionado, llegando las quejas hasta el propio monarca, quien acabó solicitándoles el doble de lo que habían negociado con mediación del presidente de la Chancillería. El resultado fue ejemplarizante para el resto de tribunales y dio más argumentos a los comisionados dispersos por la geografía para recaudar mediante el uso de la fuerza ${ }^{51}$.

Los conflictos jurisdiccionales tan frecuentes en el Antiguo Régimen también se dieron en la recaudación del donativo. Celosas de sus preeminencias, las Chancillerías buscaron cualquier subterfugio legal para impedir, o al menos retrasar, las actuación de los comisionados en lo que consideraban sus competencias. Así, la Chancillería de Granada se negó a liberar a los presos a los que Luis Gudiel había indultado. Argumentaban para ello que la cédula que presentaba el comisionado era de carácter general, y que para cada indulto era preciso una cédula particular de la Cámara de Castilla ${ }^{52}$.

48. Carta de la ciudad de Ciudad Rodrigo a Su Majestad, 27 agosto de 1637. AGS, CJH, 785.

49. Carta de Francisco Valcárcel a la Junta del Donativo de 4 de septiembre de 1637. AGS, CJH, 785.

50. Fortea Pérez, J. I.: «El Donativo de 1625 en el realengo andaluz», op. cit.

51. Cartas de Queipo de Llano a la Junta del Donativo, 1636. AGS, CJH, 763. Y «relación de los que ha pasado en Valladolid sobre el donativo que está pidiendo en aquella ciudad y obispado el gobernador de aquella chancillería, el Ldo. don Juan Queipo de Llano», AGS, CJH, leg. 1.753, citado en Fortea Pérez, J. I.: «Los donativos en la política fiscal...», op. cit.

52. Carta de Luis Gudiel a Juan Valero de 22 de diciembre de 1635. AGS, CJH, 754. 
Pero los mayores conflictos sobrevinieron cuando los comisionados solicitaron a los ministros de las Chancillerías y Audiencias un cuantioso donativo, el cual ascendía nada menos que a la tercera parte del sueldo de tres años. La cantidad era extraordinariamente elevada pues se consideraba, tal y como planteaba Fernández de Navarrete, que los ministros del rey debían ser los primeros en dar ejemplo con cuantiosos donativos ${ }^{53}$. Esta medida, como era de esperar, produjo una oleada de memoriales de ministros pidiendo ser excluidos de la contribución, o que al menos esta fuese más reducida. Resulta llamativo que los primeros en presentar memoriales a la Junta pidiendo ser excusados fueran los propios comisionados para el donativo, quienes planteaban como motivo principal que los gastos de sus comisiones habían salido de sus propias haciendas, por lo que les resultaba imposible ofrecer tal cuantía como donativo.

El estamento eclesiástico fue, junto a las oligarquías locales, el elemento que más quebraderos de cabeza causó a los miembros de la Junta y a los comisionados. Los familiares de la Inquisición desde el principio estaban incluidos en las instrucciones que se les dieron a los comisionados, advirtiendo, además, que estos solían ser hombres de fortuna, por lo que sus aportaciones debían ser cuantiosas. El dilema se planteaba al tratar de hacer participar a los clérigos, pues si se negaban a ofrecer un donativo no se podrían usar con ellos métodos coercitivos de ningún tipo. Además, se presentaba nuevamente la alternativa de si solicitarles el donativo de forma particular o por comunidades, pues si bien las instrucciones generales habían prohibido a los comisionados recaudar aportaciones de los municipios, nada decían en relación a las comunidades eclesiásticas. Salvo al alto clero, al que se le solicitó un donativo personal, el resto del estamento eclesiástico participó agrupado en sus propias comunidades.

Los familiares de la Inquisición trataron de eximirse del donativo, pero una carta del Inquisidor General instándoles a participar venció las resistencias ${ }^{54}$. De los clérigos en cambio se trató de obtener contribuciones concienciándolos de la mala situación de una monarquía que actuaba en defensa de la fe católica. Así, hubo cabildos que se negaron a participar ya que entendían que de esa forma se mancillaba el honor de su estamento ${ }^{55}$, en tanto que otros colaboraron sin problema, como el cabildo de Coria que donó 500 ducados $^{56}$, o el del obispo de Ciudad Rodrigo que además de ofrecer 400 ducados sirvió de mediador en el conflicto entre los regidores y el comisionado Francisco de Valcárcer ${ }^{57}$. A pesar de la resistencia, la

53. Fortea Pérez, J. I.: «Los donativos en la política fiscal...», op. cit., p. 42.

54. Carta de Gaspar de Bracamonte de 7 de mayo de 1637. AGS, CJH, 769.

55. Carta de Gaspar de Bracamonte a Juan Valero, 10 de febrero de 1636. AGS, CJH, 769.

56. Carta de Francisco de Valcárcel a la Junta del Donativo, 21 de julio de 1637. AGS, CJH, 785.

57. Carta del obispo de Ciudad Rodrigo a la Junta del Donativo, 27 de agosto de 1637. AGS, $\mathrm{CJH}, 785$. 
mayoría de los cabildos eclesiásticos a los que se les solicitó donativo acabaron contribuyendo. El ejemplo lo encontramos en el cabildo de Sevilla, que escribió a su agente en Roma, Diego de Zúñiga, para recibir el beneplácito papal antes de aprobar el donativo, retrasando así el trámite. Tras una intensa negociación con presiones desde la Corte, el cabildo acabó cediendo al otorgar un sustancioso servicio de 40.000 ducados $^{58}$.

Algunos de los miembros de la nobleza titulada trataron también de excusarse ante los comisionados, alegando haber aportado el donativo correspondiente en la Corte o haber servido a la corona con otras aportaciones, tales como el reclutamiento de unidades para el ejército ${ }^{59}$. La actuación de los comisionados en estos casos fue notificar a la Junta, quien a su vez trataba de verificar los servicios que habían prestado y, en función de los mismos, eximirlos o solicitarles un donativo menor.

La cobranza de las cantidades ofrecidas planteaba también diversos problemas. Los términos del debate los expresaba Francisco de Valcárcel el 29 de agosto de 1637 cuando escribía: «solo digo que es importantísimo para asegurarse el donativo el hacer que el concejo, justicia y regimiento de cada lugar se encargue de la cobranza como hasta ahora aquí se ha hecho en el obispado de Plasencia» ${ }^{60}$. En Sevilla también insistía Gaspar de Bracamonte a la Junta en que era necesario que el cobrador elegido fuese un miembro reconocido de la oligarquía local con poderes para embargar a todos aquellos que hubiesen firmado escritura de obligación ${ }^{61}$. El objetivo que pretendían ambos comisionados era ganar algunos aliados entre las oligarquías que garantizaran el cumplimiento de los pagos una vez que marchasen de la ciudad. También se delegó con frecuencia en los corregidores para cobrar los pago aplazados del donativo, e incluso se nombraron depositarios y cobradores en los municipios que debían posteriormente remitir los caudales y las cuentas a los comisionados o bien directamente a la Junta. Por último, para los lugares en los que no se había seguido uno de estos métodos se despacharon ejecutores que cobrasen las obligaciones de pago contraídas por los vecinos. El sistema de cobranzas fue por tanto extremadamente variado, haciendo uso de las estructuras administrativas existentes, creando otras nuevas, e incluso aprovechando el poder de las élites locales, como elementos de intermediación.

58. Carta de Gaspar de Bracamonte a la Junta del Donativo, 28 abril de 1637. AGS, CJH, 769.

59. El marqués de Villanueva trató de excusarse por haber levantado una compañía de soldados en la que gastó más de 6.000 ducados. Carta de Gaspar de Bracamonte a la Junta del Donativo, 21 abril de 1637. AGS, CJH, 769. 785.

60. Carta de Francisco de Valcárcel a la Junta del Donativo, 27 de agosto de 1637. AGS, CJH,

61. Carta de Gaspar de Bracamonte a Juan Valero, 10 de febrero de 1637. AGS, CJH, 769. 
FRANCISCO GIL MARTÍNEZ

DE LA NEGOCIACIÓN A LA COERCIÓN: LA RECAUDACIÓN DEL DONATIVO DE 1635

\section{Conclusión}

En el complejo panorama fiscal del Antiguo Régimen, los donativos fueron un elemento bastante arcaico al establecer directamente una dialéctica entre soberano y súbdito, evitando así cualquier tipo de regulación. La mayoría de los autores que se han acercado al fenómeno habían visto indicios que venían a refutar la voluntariedad de los donativos, destacando en este sentido las aportaciones de Domínguez Ortiz ${ }^{62}$. El adjetivo de «gracioso» que solía acompañarlos se tornaba así en una broma de mal gusto para los súbditos castellanos. No obstante, a pesar de no haber caído en el engaño de la voluntariedad desconocíamos los medios utilizados para forzar a la población, en parte porque la propia administración de la época se había ocupado de silenciar, bajo una artificiosa opcionalidad, el ruido de las quejas contra las prácticas abusivas de los comisionados. El donativo de 1635, si bien era una réplica de la estructura institucional desplegada en la ocasión de 1629, utilizó métodos coercitivos de diversa índole, especialmente contra las clases acomodadas. Debemos situar, por tanto, el donativo de 1635 en línea con impuestos y derechos como la media annata, los impuestos de lanzas, el papel sellado o el impuesto de la sal, intentos innovadores todos ellos de obtener ingresos de las clases altas de la sociedad castellana que gracias a sus privilegios evitaban otro tipo de contribuciones.

Aunque el uso y las formas de coerción por parte del Estado en esta petición constituyen la principal novedad del donativo de 1635 respecto a los anteriores, la petición contó también con una serie de características prácticamente únicas entre los mecanismos de recaudación estatales. Por un lado fue obtenido de todos los súbditos castellanos, prácticamente sin excepciones, pues participaron los estamentos que tradicionalmente habían estado exentos de tributaciones. Sortear los fueros y privilegios de los diferentes grupos sociales supuso, como hemos visto, un enorme esfuerzo para los ministros regios, pues estos se resistieron a perder sus privilegios. Por otra parte, el donativo no solo igualó a los súbditos castellanos en su participación, sino que los distinguió en función de su riqueza, solicitando cantidades mayores a los más ricos. Constituyó pues una vía de ingresos fiscales proporcional a la riqueza, siendo una verdadera excepción en el panorama hacendístico del Antiguo Régimen. A pesar de que el donativo no obtuvo un mal resultado recaudatorio, si tenemos en cuenta la situación económica del país, la cantidad de conflictos que suscitó impidió que se volviesen a utilizar los mismos métodos. Este donativo quedó por tanto como una medida extraordinaria fruto de la pésima situación hacendística del periodo y de las urgencias de la guerra.

62. Domínguez Ortiz, A.: «La desigualdad contributiva en Castilla...», op. cit. 
FRANCISCO GIL MARTÍNEZ

DE LA NEGOCIACIÓN A LA COERCIÓN: LA RECAUDACIÓN DEL DONATIVO DE 1635

\section{BiBLIOGRAFÍA}

Baltar Rodríguez, J. F.: Las juntas de gobierno de la monarquia hispánica: (siglo XVI-XVII). Madrid, Centro de Estudios Políticos y Constitucionales, 1998, pp. 282-288.

CÁrceles de Gea, B.: «Del juez de comisión al comisario real (1632-1643). El fraude fiscal como agente del «gobierno económico»», Studia Historica. Historia Moderna, 13, pp. 155-156.

Domínguez Ortiz, A.: «La comisión de D. Luis Gudiel para la venta de baldíos de ANDALUCíA», en Congreso de historia rural: siglos XV-XIX: actas del coloquio celebrado en Madrid, Segovia y Toledo del 13 al 16 de octubre de 1981. Madrid, Universidad Complutense, 1984, pp. 511-522.

Domínguez Ortiz, A.: Política y Hacienda de Felipe IV, Madrid, Editorial de Derecho Financiero, 1960, pp. 297-314.

Domínguez Ortiz, A.: «La desigualdad contributiva en Castilla durante el siglo Xviı», en Instituciones y sociedad en la España de los Austrias. Barcelona, Ariel, 1985.

Elliott, J. H.: El conde-duque de Olivares: el político en una época de decadencia. Barcelona, Crítica, 1998.

Espejo Hinojosa, C.: «Preliminares en Madrid y su jurisdicción del Donativo de 1625», Revista de la Biblioteca, Archivo y Museo de la Comunidad de Madrid, 8, 1925, pp. 553-559.

Esteban Estríngana, A. (ed.): Servir al rey en la monarquía de los Austrias medios, fines y logros del servicio al soberano en los siglos XVI y XVII. Madrid, Sílex, 2012.

Fortea Pérez, J. I.: «Doctrinas y prácticas fiscales», en González Lopo, D. y López López, R. J. (eds.): Balance de la historiografía modernista: 1973-2001: Actas del VI Coloquio de Metodología Histórica Aplicada (Homenaje al profesor Antonio Eiras Roel). Santiago de Compostela, Xunta de Galicia, 2003.

Fortea Pérez, J. I.: «El Donativo de 1625 en el realengo andaluz», en Marcos Martín, A. (ed.): Hacer Historia desde Simancas. Homenaje a José Luis Rodríguez de Diego. Valladolid, Junta de Castilla y León, 2011, pp. 317-338.

Fortea Pérez, J. I.: «Los donativos en la política fiscal de los Austrias (1625-1637): ¿servicio o beneficio?» en Riвot García, L. y Rosa, L. (eds.): Pensamiento y política económica en la época moderna. Madrid, 2000, pp. 31-76.

Gelabert González, J. E.: La bolsa del rey: rey, reino y fisco en Castilla: (1598-1648). Barcelona, Grijalbo, 1997.

Gómez González, I.: «Más allá de la colegialidad. Una aproximación al juez de comisión en la España del Antiguo Régimen», Chronica Nova, 37, 2011, pp. 21-40.

LANZa García, R.: «El donativo de 1629 en el distrito de Fernando Ramírez Fariñas» en Bilbao, L. M., Lanza, R., Álvarez, C., y Andrés, J. I. (eds.): IX Congreso Internacional de la Asociación Española de Historia Económica. Murcia, 2008, pp. 1-37.

LANZA García, R.: «El donativo de 1629 en la Andalucía Bética», Studia Historica. Historia Moderna, 32, 2010, pp. 179-227. 
LANZa GARcía, R.: «El donativo de las guerras de Italia (1629): estudio del caso del Arzobispado de Toledo y la provincia de Guadalajara», Obradoiro de Historia Moderna, 19, 2010, pp. 125-159.

Marcos Martín, A.: «¿Fue la fiscalidad regia un factor de crisis en la Castilla del siglo xvir?» en Parker, G. (ed.): La crisis de la monarquía de Felipe IV. Madrid, Crítica, 2006, pp. 173-254.

Porres Marijuán, R.: «Las contribuciones vascas a la Hacienda Real en la Edad Moderna: algunos contrastes provinciales», Obradoiro de Historia Moderna, 19, 2010, pp. 87-124.

Quintanilla González, R.: «¿ Obejo, Córdoba y otras villas de su jurisdicción pagaron el donativo de 1629?», Crónica de Córdoba y sus pueblos, 16, 2009, pp. 263-330.

Ruiz Martín, F.: «Procedimientos crediticios para la recaudación de los tributos fiscales en las ciudades castellanas durante los siglos Xvi y Xvir: el caso de Valladolid» en Otazu y Llana, A. (ed.): Actas del I Coloquio Internacional de Historia Económica. Dinero y Crédito (siglos XVI al XIX). Madrid, 1978, pp. 37-47.

Sánchez González, D. M.: El deber de consejo en el Estado Moderno: las juntas "ad hoc» en España (1474-1665). Madrid, Polifemo, 1993.

Truchuelo García, S.: «Donativos y exenciones: en torno a los servicios monetarios de las provincias vascas en el siglo XvII», comunicación presentada al IX Congreso Internacional de la Asociación Española de Historia Económica, Murcia, 2008, disponible en http://www.um.es/ixcongresoaehe/pdfB2/Donativos.pdf [consultado el 21/04/2015].

Truchuelo García, S.: «Privilegios y libertades fiscales: los donativos al monarca en los territorios vascos y Cataluña en el período altomoderno», Pedralbes: Revista d'bistoria moderna, 28, 2008, pp. 283-299. 